\title{
Omgewingsopvoeding se rol in die integrasie van omgee vir die omgewing en menslike welstand
}

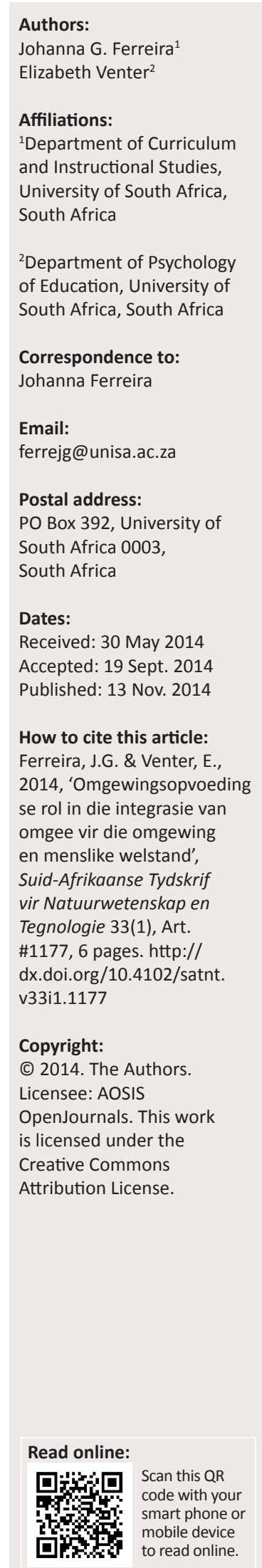

Welstand hou nie slegs verband met die afwesigheid van siekte nie, maar behels optimale funksionering van liggaam, verstand en gees. Dit is 'n belewenis van maksimale harmonie. Welstand het verskeie dimensies, naamlik die fisieke, emosionele, kognitiewe, sosiale, geestes-, beroeps- en omgewingsdimensies. Laasgenoemde is die mees waarneembare en noodsaaklike dimensie vir die voortbestaan van die mensdom. Hierdie artikel gaan van die standpunt uit dat welstand binne die dimensie van die omgewing interafhanklik is van omgee vir die omgewing en dat hierdie welstand slegs volhoubaar sal wees indien kinders van kleins af blootgestel word aan aktiwiteite in die natuur. Die rol van omgewingsopvoeding in die vestiging van 'n etiek van omgee en aktiewe besorgdheid vir die omgewing, is onbetwisbaar en is noodsaaklik vir menslike welstand.

The role of environmental education in the integration of care for the environment and human wellness. Wellness is not merely the absence of illness, but a state of optimal functioning of body, mind and soul. It is a situation where harmony is experienced maximally. Wellness has various dimensions, namely the physical, emotional, cognitive, spiritual, social, vocational and environmental dimensions. The latter is the most conspicuous and essential for the continued existence of humankind. The point of departure of this article is that wellness within the environmental dimension is interdependent on care for the environment and that this wellness will only become sustainable if children are exposed to activities in nature from an early age. The role of environmental education in establishing an ethic of care and active concern for the environment, is non-negotiable and essential for human wellness.

\section{Inleiding}

Welstand is nie 'n nuwe begrip nie en spesifieke verwysing na die welstand van die mens en gemeenskap op 'n hoë vlak het reeds in die vyftigerjare voorgekom. Dunn (1959) beweer dat die fokus op welstand begin is deur die omskrywing van die fundamentele doelwit van die World Health Organization (Wêreldgesondheidsorganisasie) dat gesondheid as 'n staat van totale fisieke, geestes- en sosiale welstand gereken moet word en nie bloot verwys na die afwesigheid van siekte en gebrek nie. Myers (1991) wys ook daarop dat welstand nie dieselfde as fisieke gesondheid is nie. Welstand verwys gevolglik na die samesmelting van liggaam, verstand en gees met die klem op 'n gebalanseerde lewenstyl as beide proses en doelwit (Archer, Probert \& Gage 1987; Warner 1984). Angeli (2014) beklemtoon dat die omgewing menslike gesondheid en welstand direk beïnvloed. Die mens se omgewing het die potensiaal om algehele welstand te bevorder. Gevolglik kan die afhanklikheid van die mens van die omgewing vir welstand en sosiale onwikkeling nie gering geag word nie (Norström et al. 2014). Costanza (2013) en Yang et al. (2013) stel dit dat die mens tans nie volhoubare omgewingswelstand bemeester nie; inteendeel, daar word toenemend in die teenoorgestelde rigting beweeg en eerder bygedra tot die verwoesting van die omgewing.

In hierdie artikel word die konsep 'welstand' en die interafhanklikheid daarvan met omgee vir die omgewing as deel van omgewingsopvoeding ondersoek deur middel van 'n literatuurstudie. Die klem in hierdie artikel val slegs op die dimensie van die omgewing as deel van die algehele welstand van die mens. Die voortbestaan van mense binne hierdie dimensie vereis dat individue die verantwoordelikheid sal aanvaar om die volhoubaarheid van hul onmiddellike omgewing te verseker en voortvloeiend daaruit ook van die globale wêreld. Omgewingsopvoeding speel 'n belangrike rol om te fokus op die mens se ingesteldheid teenoor die omgewing, want omgee vir die omgewing gaan nie net oor die geleenthede om deel te wees van die omgewing nie, maar ook oor die houding van die mens teenoor die omgewing (Lin et al. 2014). Die beweegrede vir hierdie studie is om die klem te laat val op die rol van die omgewing in menslike welstand, veral op die aanleer van omgee en respek vir die omgewing deur omgewingopvoeding. Omgewingsopvoeders se aandeel aan menslike 
welstand deur, onder andere, om te gee vir die natuurlike omgewing en elke individu se bydrae daartoe, vorm die fokus van hierdie literatuurstudie.

\section{Die begrip 'welstand'}

Daar is geen enkele, algemeen aanvaarbare definisie van menslike welstand nie en dié konsep word as 'n breë en dikwels omstrede begrip beskou. Welstand word gereeld aan gesondheid gekoppel, maar soos Miller (2005) dit stel, wissel welstand van een konteks na 'n ander en is dit die produk van 'n komplekse vormingsproses wat 'n enkele definisie daarvan bemoeilik. Gevolglik gebruik Prilleltensky (2012) die woorde 'welsyn' (of welwees) en 'welstand' afwisselend, maar met dieselfde betekenis. Die rede hiervoor is dat beide begrippe' $n$ positiewe bestaan impliseer wat tot stand gebring word deur die gelyktydige en gebalanseerde bevrediging van verskillende objektiewe en subjektiewe behoeftes van individue en gemeenskappe (Prilleltensky 2012). Hierdie artikel gee uitdrukking aan dieselfde siening, alhoewel die begrip 'welstand' hier meer beklemtoon word.

Soos Prilleltensky (2012) tref Summers et al. (2012) ook onderskeid tussen die objektiewe en subjektiewe dimensies van welstand. Volgens hierdie outeurs hou die objektiewe dimensie verband met materiële en sosiale eienskappe wat die welstand van individue en gemeenskappe kan bevorder of benadeel. Dit sluit onder andere die vlak van rykdom, voorsiening van opvoedingsgeleenthede, gesondheidsorg en infrastruktuur van 'n individu of gemeenskap in. Dit kan algemeen beskou word as basiese behoeftes, ekonomiese behoeftes en omgewingbehoeftes wat as belangrik vir die samelewing geag word en wat maklik meetbaar is. In teenstelling hiermee ondervang die subjektiewe dimensie 'n individu se siening van sy of haar eie omstandighede, met ander woorde wat die individu self dink en voel. Dit verwys derhalwe na die welstand wat 'n bepaalde indivuduele persoon ervaar.

Welstand moet gevolglik as 'n multidimensionele begrip beskou word wat mense se lewensomstandighede, met ander woorde hoe hulle voel en funksioneer, weergee. Diener en Seligman (2004:1) meld die volgende oor welstand: '... people's positive evaluations of their lives, includes positive emotion, engagement, satisfaction and meaning.' ['Mense se positiewe waardering van hul lewens sluit positiewe emosie, betrokkenheid, bevrediging en betekenis in.'] Samevattend word welstand derhalwe beskou as'n positiewe fisieke, sosiale en geestestoestand. Soos vroeër gemeld, gaan welstand nie slegs oor die afwesigheid van pyn, ongemak en onvermoë nie, maar dat basiese behoeftes bevredig word, dat individue 'n doel en betekenis in hul eie lewe het en ook voel dat hulle 'n bydrae binne hul gemeenskap kan lewer. Hierbenewens word welstand verder volgens Summers et al. (2012:328) bevorder deur '... supportive personal relationships, strong and inclusive communities, good health, financial and personal security, rewarding employment, and a healthy attractive environment'. ['... ondersteunende persoonlike verhoudings, sterk en inklusiewe gemeenskappe, goeie gesondheid, finansiële en persoonlike sekuriteit, lonende werk, en 'n gesonde aantreklike omgewing'.] Hierdie siening stem ooreen met dít wat Callicot (1996) dekades gelede gemeld het, naamlik dat benewens fisieke welstand, ses ander dimensies van welstand geïdentifiseer kan word, te wete emosionele, kognitiewe, sosiale, geestes-, beroeps- en omgewingsdimensies. Hierdie dimensies is interafhanklik en nou met mekaar verweef. Mens kan byvoorbeeld nie emosionele welstand ervaar as daar onbevredigende sosiale verhoudings heers nie; so ook kan mense nie fisiek gesond wees as die omgewing hoogs besoedeld is nie. Shuster-Gansrow (2011) som welstand op deur te verwys na fisieke welstand waarin dieet, oefening en algemene gesondheid ' $n$ rol speel; finansiële welstand waar mense finansieel selfversorgend is en in ' $n$ beroep staan; sosiale welstand wat gesonde familie-, vriendskaps- en meer intieme verhoudings insluit, sowel as geestelike, emosionele, kognitiewe en omgewingswelstand. Reese en Myers (2012) voeg by dat welstand as 'n lewenswyse geag kan word wat gerig is op optimale gesondheid en welsyn waarin liggaam, verstand en gees deur ' $n$ individu geintegreer is om voluit in 'n menslike en natuurlike gemeenskap te lewe. Die belangrikste afleiding wat uit voorafgaande omskrywings gemaak kan word, is dat welstand gesien moet word as iets multidimensioneels wat mense se lewensomstandighede, hul denke en gevoelens insluit, asook die optimale funksionering van die mens omvat. Van al die dimensies van welstand is dié van die omgewing die mees waarneembare dimensie.

Die kwaliteit van die omgewing het 'n pertinente invloed op die mens se algehele gesondheid en welstand (Callicot 1996). Gevolglik is die welstand van die omgewing net so noodsaaklik vir die mens se gesondheid en algehele welstand soos al die ander dimensies. Die Millennium Ecosystem Assessment gee 'n goeie samevatting van die interaksie tussen die natuurlike omgewing en fisieke, geestes- en sosiale welstand en beklemtoon die feit dat welstand nie in isolasie van die natuurlike omgewing gesien kan word nie (Millenium Ecosystem Assessment 2005). Callicot (1996:146) beweer: 'We cannot pursue personal wellness unless we also work collectively and cooperatively to ensure an improvement in our natural and fabricated environments'. ['Ons kan nie persoonlike welstand ten doel hê tensy ons gesamentlik en samewerkend 'n verbetering in ons natuurlike en mensgemaakte omgewings verseker nie'.] Dit is gevolglik noodsaaklik dat verdere agteruitgang van die omgewing verhoed moet word en dat ' $n$ poging aangewend word om omgewings wat reeds beskadig is, te herstel. Hierbenewens is dit belangrik om 'n gesindheid van omgee deur omgewingsopvoeding te ontwikkel en sodoende volhoubare eko-welstand aan toekomstige nageslagte na te laat.

\section{Teoretiese raamwerk}

Wanneer na die omvattendheid van die begrip 'welstand' gekyk word, verskaf die sisteemteorie 'n goeie onderbou in die bespreking van die verskillende dimensies. Bronfenbrenner (1989) verklaar in sy bio-ekologiese teorie (wat direk verband hou met die sisteemteorie) dat omgewings 
dinamies en veranderend van aard is. Alle mense leef en groei in omgewings of sisteme met subsisteme wat bestaan uit allerlei omgewingsinvloede, byvoorbeeld die gesins-, opvoedings-, gemeenskaps-, sosiale en kulturele invloede. Die konteks waarin mense grootword, is dus baie belangrik vir hul ontwikkeling, omdat konteks alle interne en eksterne sisteme behels wat in wisselwerking is met die individu se denke, gevoelens en gedrag, en sodoende ontwikkeling en leer beïnvloed (Woolfolk 2013). Die ekologiese deel van Bronfenbrenner se teorie wys op die interafhanklikheid van organismes en hul omgewing. Dit moet holisties verreken word, omdat samewerking van alle subsisteme noodsaaklik is vir oorlewing van die sisteem as geheel. Die sisteem as geheel sal slegs kan voortbestaan as daar balans tussen al die subsisteme is (Donald, Lazarus \& Lolwane 2012).

Bronfenbrenner (1989), Keenan en Evans (2009) en Woolfolk (2013) noem verskeie sisteme wat 'n invloed het op alle individue, te wete mikrosisteme, soos vriende, die gesin en opvoeders; mesosisteme, wat interaksies en verhoudings tussen persone in die mikrosisteem behels soos tussen lede van die huisgesin en opvoedingsinstansies of die direkte omgewing; eksosisteme, wat sosiale kontekste soos opvoedings- en werksomgewings insluit, asook ontspanningsentrums en sosiale ondersteuningsnetwerke; makrosisteme, waaronder waardes, wette, tradisies en konvensies ressorteer, en chronosisteme wat historiese tyd en gebeure omvat. Dis veral in mesosisteme en eksosisteme waar die vestiging van omgee, en gevolglike omgewingsverwante welstand, ter sprake is. Binne die opvoedingsisteme van 'n individuele kind speel al die subsisteme 'n rol. Leer binne gesinsverband sal byvoorbeeld beïnvloed word deur die sosio-ekonomiese konteks, sowel as die kognitiewe en emosionele ondersteuning wat die kind ontvang. Die beskikbaarheid van hulpbronnne sal byvoorbeeld ' $n$ invloed op die sisteem as geheel hê. In agtergeblewe groepe sal kinders nie noodwendig hulpbronne in hul nabye omgewing hê nie en moontlik ook nie in die skole waar hulle skoolgaan nie, wat meebring dat hulle nie in alle dimensies wat vroeër vermeld is na wense kan ontwikkel nie. Op 'n ander vlak sal die waardes wat die kinders aanleer in hul nabye omgewing (ook ekologiese waardes), in wisselwerking tree met wat in die skool, gemeenskap en in die breër samelewing oorgedra word. Indien die waardes nie alle subsisteme betrek nie, sal kinders dit moeilik vind om dit hul eie te maak (Donald et al. 2012). Om byvoorbeeld die waarde van omgee aan te leer en hul eie te maak, moet kinders binne die sisteem as geheel daaraan blootgestel word. Kinders wat skaars oorleef en wie se basiese behoeftes nie bevredig word nie, sal moeilik waardes soos omgee, ontwikkel. Die individuele kind is gevolglik vir algehele welstand afhanklik van insette by die huis, die skool, die plaaslike gemeenskap, die breër samelewing, wat die Staat en die nodige beskikbaarstelling van hulpbronne en wetgewing insluit. Al genoemde sisteme speel 'n rol wanneer daar na die interaksie tussen welstand, omgee vir die omgewing en omgewingsopvoeding gekyk word.

\section{Omgee vir die omgewing se bydrae tot welstand}

Die begrip 'omgee' is reeds deel van opvoeding sedert die tyd van die Griekse filosowe Plato en Sokrates. Kinders het in daardie era geleer om vir mekaar om te gee, om wysheid, deugsaamheid en waarheid na te streef en sodoende ook vir die gees om te gee. Heidegger beklemtoon in Being and Time (1996) dat die mens se in die wêreld wees in essensie 'omgee' beteken. Ook Gadamer (1993 in Mortari 2004) beweer dat die mens in wese iemand wil wees wat omgee, asook vir wie omgegee word. Die pedagogiese onderbou van omgee is derhalwe reeds vir eeue deur kinders aangeleer en gevolglik is die beklemtoning daarvan bloot die erkenning van 'n noodsaaklike menslike eienskap. Die ontwikkeling van omgee vir alle lewende wesens, asook die nielewende omgewing, moet egter meer aandag geniet om 'n ekologiese etiek te vestig, waar verantwoordelikheid en omgee, hand aan hand gaan (Mortari 2004).

In teenstelling met mensgesentreerde etiek, behoort 'n morele oriëntasie ontwikkel te word waarvolgens alles wat lewe, waarde het. Die ontologiese voorveronderstelling (wat die basis van Westerse etiek is waar die natuur as instrumenteel gesien word tot voordeel van die mens), behoort te verander na 'n siening waar die mens as deel van die natuur gesien word - 'n holistiese siening. Elke lewende wese in die natuur sal dan as ewe waardevol beskou word en as sodanig gerespekteer word. Dit is veral die feministiese beweging wat begin verwys het na 'n 'etiek van omgee' met 'n morele gesindheid jeens omgee en respek vir alles wat lewe omsluit (Mortari 2004). Noddings (1984, 1992, 2012) som die konsep 'omgee' op as 'n konseptuele en affektiewe begrip; as positiewe ontsag en respek vir die gevoelens en intrinsieke waardes van ander individue, asook van diere, plante en nielewende dinge; die erkenning van elk se regte; en die motivering, gewilligheid en nodige vaardighede om op te tree, in te gryp en te beskerm en om ooreenstemmende gevoelens, waardes en regte te versterk. 'Omgee' behels gevolglik ' $n$ positiewe ingesteldheid en meelewendheid en lei tot die vestiging van ' $n$ verhouding tussen 'n persoon wat omgee en dít waarvoor omgegee word. Die persoon wat omgee, luister gewoonlik aandagtig, neem waar, en is ontvanklik vir die behoeftes van ander vir wie daar omgegee word. Die persoon wat omgee, behoort op hierdie behoeftes te reageer en moet ingryp waar nodig. Die voorwerp van dié soort besorgdheid, sal daarop reageer wat weer daarop sal dui dat die omgee 'n invloed het en dat dit wel ontvang en ervaar word. Wederkerigheid en 'n onderlinge verwantskap is belangrik in hierdie verhouding. Die etiek van omgee is 'n konteksgebaseerde, wederkerige etiek wat uit morele ontwikkeling spruit in die verhouding tussen die persoon wat omgee en dít waarvoor omgegee word.

Volgens omgewingsopvoeders is dit nodig om ' $\mathrm{n}$ teoretiese begrip van omgewingsprobleme te hê, maar groter klem behoort op die affektiewe dimensie geplaas te word sodat kinders 'n positiewe omgewingsetiek aanleer en uitleef. 
Omgewingsverwante kennis moet gevolglik sover moontlik met ervaring gekombineer word, veral deur direkte belewing van die omgewing - daar word kinestetiese, kognitiewe en emosionele verbindings gemaak indien dit persoonlik ervaar word. Soos vroeër gemeld, is 'n 'etiek van omgee' konteksgebonde en is dit 'n verhouding tussen die persoon wat omgee en die ontvanger van die welwillendheid. Morele ontwikkeling kan derhalwe deur ervarings in die omgewing gevestig word. Die ontwikkeling van 'n persoonlike verhouding met die natuur behoort 'n belangrike doelstelling van omgewingsetiek te wees wat weer na persoonlike en gesamentlike aanspreeklikheid vir die omgewing sal lei en welstand sal meebring. Goralnik et al. (2012) is oortuig daarvan dat ' $n$ omgewingspedagogie van omgee sentraal in die kurrikulum sal staan as dit 'n belangrike doelstelling van omgewingsetiek is om ' $\mathrm{n}$ persoonlike verhouding met die natuurlike wêreld te ontwikkel. Hierbenewens moet 'n waardevolle uitkoms van hierdie leer 'n persoonlike en gesamentlike verantwoordelikheid vir mense, plekke, en idees vorm, asook die aanleer van 'n omgewingsetiek wat nie slegs belang het in kennis van omgewingskwessies en waardekonflik nie, maar ook in 'n ingesteldheid van omgee. Dit skep 'n basis vir volhoubare welstand veral binne die dimensie van die omgewing.

\section{Integrasie van omgee vir die omgewing en welstand in omgewingsopvoeding}

Alhoewel omgewingskwessies aandag in skoolkurrikula kry, beweer Noddings (1984:135) die volgende: 'Schools give some attention to environmental problems, but they are not giving enough to the development of caring human beings.' ['Skole gee aandag aan omgewingskwessies, maar hulle dra nie genoegsaam by tot die ontwikkeling van besorgde mense wat omgee nie.'] Noddings (1992) pleit dat kinders reeds vroeg in hul lewe 'n etiek van omgee hul eie sal maak; daarom behoort skole eerder as sentrums van omgee beskou te word, waar kinders nie net leer om vir hulself en ander naby aan hulle om te gee nie, maar vir alles in hul omgewing. Omgee kan bevorder word deur kinders aan veral hul natuurlike omgewing bloot te stel. Roszak (1992) verwys na die beskouing dat alle mense 'n 'ekologiese onbewuste' het wat ontvou wanneer daar genoegsame skakeling met die natuur is. Eko-welstand word sodoende deel van die holistiese welstand van die kind. Blootstelling aan die natuurlike omgewing, hetsy deur visuele beelde in die media of deur direkte ervaring, het ' $n$ positiewe fisieke en emosionele invloed op menslike welstand. Nisbet, Zelenski en Murphy (2011) bevestig dat blootstelling aan die natuur 'n positiewe effek op mense het, selfstandigheid en persoonlike groei meebring en lewensdoelstellings en selfaanvaarding bevorder.

Nieteenstaande voorgaande sentiment stel Louv (2005) dit dat kinders tans in veral stedelike gebiede, nie voldoende blootstelling aan die natuur kry nie. Die outeur verwys na 'n 'sindroom' wat ontwikkel vanweë 'n gebrek aan blootstelling aan die natuur. Daar is verskeie redes vir die ontstaan daarvan. Ouers vrees vir hul kinders se veiligheid en kinders word derhalwe meesal binnenshuis groot, maar hierbenewens dra tegnologiese en elektroniese vermaak by tot ' $n$ gebrek aan belangstelling en aktiwiteite in die natuur. Kinders wend nie 'n poging aan om buite te speel nie. Die tekort aan natuurlike blootstelling aan die omgewing beïnvloed kinders se ontwikkeling in die algemeen, maar veral op emosionele gebied. Volwassenes, wat as kinders blootstelling aan natuurervarings gehad het, toon ' $\mathrm{n}$ meer gevestigde sensitiwiteit jeens die omgewing in vergelyking met diegene wat nie soortgelyke ervarings gehad het nie (Summers et al. 2012; Wells \& Lekies 2006). Dit blyk egter dat daar tans nie genoeg mense is wat omgee vir hul omgewing nie, wat dalk reeds 'n aanduiding van die moontlike leemte in omgewingsopvoeding is. Hart (2003) beweer dat alhoewel omgewingskwessies in omvang toeneem en dit volhoubare welstand bedreig, blyk dit dat mense in daardie stadium minder deelneem aan aksies om hul ontevredenheid oor omgewingskwessies uit te spreek. Gevolglik moet die belangrikheid van die omgewing vir gesondheid en welstand van die mens 'n prioriteit word in omgewingsopvoeding.

Unesco (1977 in Weinstein \& Rosen 2003) stel drie doelstellings vir omgewingsopvoeding, naamlik dat dit 'n bewustheid van en besorgdheid oor die interafhanklikheid van die ekonomiese, sosiale, politieke en ekologiese dimensies in die omgewing as geheel moet kweek; dat dit geleenthede behoort te skep vir elke persoon om kennis, waardes, houdings en vaardighede aan te leer om die omgewing te beskerm en te verbeter; en dat dit nuwe gedragspatrone by individue, gemeenskappe en die breër samelewing ten opsigte van die omgewing behoort te skep. Weens die tekort aan blootstelling, hetsy vanweë oorbeskerming van ouers of onbetrokkenheid van beide ouers en kinders, neem die belangrikheid van omgewingsopvoeding daagliks toe om die voorgaande doelstellings te bereik. Alhoewel omgewingsopvoeding hoofsaaklik fokus op die bewusmaking van die mens se betrokkenheid by die omgewing, raak dit al hoe belangriker om kinders nie slegs aan natuurlike omgewings bloot te stel nie, maar om ook 'n gesindheid van omgee te kweek en aan hulle die nodige kennis en vaardighede te voorsien om as volwassenes hul eie welstand en dié van hul nageslag te verseker. Die toenemende druk op die omgewing beperk die vermoë van ekosisteme om volhoubaar in die noodsaaklike behoeftes van die mens te voorsien; wysig die mens se siening van tevredenheid met die natuur, en op die lang termyn, sal dit menslike welstand beduidend verminder (Summers et al. 2012; Lin et al. 2014). Deur omgewingsopvoeding kan toekomstige geslagte welstand binne die omgewingsdimensie ervaar as kinders vroegtydig aan die natuurlike omgewing blootgestel word, en volhoubaarheid kan verseker word deur 'n houding van omgee te vestig. Hierdie standpunt word deur Suzuki (1997) beaam dat die mens se verbintenis met die omgewing herontdek moet word en dat dit by die opvoeding van kinders moet begin. Hierdie opvoeding berus volgens Summers et al. (2012:331) op blootstelling en wisselwerking met die natuur: 'Interactions with nature ... have shown to enhance cognitive and problem-solving abilities, promote independence, 
focus attention, promote better environmental awareness ...' ['Interaksie met die natuur ...verbeter kognitiewe en probleemoplossingsvermoëns, bevorder onafhanklikheid, rig aandag en bevorder omgewingsbewustheid.'] Blootstelling op direkte of indirekte wyse aan die natuur is van kardinale belang vir fisieke, kognitiewe en selfs morele ontwikkeling van die mens (Kahn 1999 in Summers et al. 2012).

\section{Aanbevelings}

Deur omgewingopvoeding moet daar aandag gegee word aan 'n kurrikulum in 'n poging om kinders te leer om vir die omgewing om te gee en sodoende hul algemene welstand te probeer verseker. Kinders moet hul verhouding met die omgewing en natuurlike wêreld van kleins af eksperimenteel ondersoek om sodoende 'n positiewe eko-waardesisteem te ontwikkel wat hulle 'n sensitiewe ingesteldheid teenoor die omgewing sal gee. Die leerervaring moet derhalwe emosioneel, sowel as kognitief wees, om 'n etiek van omgee te ontwikkel (Goralnik et al. 2012). Hierbenewens behoort veral kinders wat wel 'n vrees vir die natuurlike omgewing het aan positiewe ervarings blootgestel word om dié vrees te bowe te kom. Kinders moet veilig voel om vrylik in 'n natuurlike omgewing te beweeg en te eksperimenteer en behoort 'n gesindheid van omgee vir alle lewende en nielewende wesens binne hul direkte omgewing te kweek onder die leiding van persone met 'n liefde vir die omgewing. Sodoende sal kinders mettertyd 'n wyer belangstelling, 'n sin vir verantwoordelikheid en 'n etiek van omgee vir hul onmiddellike omgewing ontwikkel wat kan lei na die oplossing van omgewingskwessies en sodoende volhoubare menslike welstand verseker. Omgewingsopvoeding is interdissiplinêr, en dit is die taak van alle onderwysers om die etiek van omgee in alle vakke toe te pas.

\section{Slot}

Om welstand in alle dimensies van menswees te ervaar, behoort die onderskeie dimensies beklemtoon te word binne ' $n$ holistiese sisteem, maar soos reeds genoem, is die dimensie van omgewing een van die mees sigbare dimensies van menswees. Gevolglik behoort mense, veral kinders, deur omgewingsopvoeding begelei te word om alle aspekte van menswees te ontwikkel met klem op omgee vir lewe en die omgewing met volhoubare menslike welstand ten doel. Binne omgewingsopvoeding kan kinders geleer word dat die omgewing ' $n$ invloed het op alle ander subsisteme van die mens in geheel en daarom moet hulle reeds van kleins af leer omgee vir hul omgewing ter wille van die volhoubare voortbestaan van elke individu, gemeenskap en ook vir die omgewing as geheel. Kinders kan volgens Weinstein en Rosen (2003) van jongs af leer omgee vir hul omgewing en behoort ook te leer dat hul welstand interafhanklik is van die welstand van die omgewing, die aarde en al die wesens daarop:
Encouraging students to develop environmentally sound habits, measures to create a way of life that coexists in harmony with the environment, will increase the possibility that our future will lead to adults who establish policies and practices that nurture the earth, discourage exploitation of its resources and then, by definition, support and respect human existence. [Deur leerders aan te moedig om omgewingsuriendelike gewoontes te ontwikkel en 'n lewenstyl wat in harmonie met die omgewing bestaan, sal die kans verbeter dat toekomstige volwassenes wetgewing en praktyke tot verbetering van die aarde daar sal stel, om uitbuiting van die aarde se hulpbronne te ontmoedig en sodoende ondersteuning en respek vir menslike bestaan verseker.] (Weinstein \& Rosen 2003:445, [outeur se eie vertaling])

Omgewingsopvoeding vervul 'n belangrike rol in die vestiging van 'n etiek van omgee vir lewe en die omgewing om sodoende by te dra tot volhoubare menslike welstand in al die dimensies, maar veral in dié van die omgewing.

\section{Erkenning Mededingende belange}

Die outeurs verklaar hiermee dat hulle geen finansiële of persoonlike verbintenis het met enige party wat hul nadelig of voordelig kon beïnvloed het in die skryf van hierdie artikel nie.

\section{Outeursbydraes}

J.G.F. (Universiteit van Suid-Afrika) se bydrae was meer oor die terrein van omgewingsopvoeding terwyl E.V. (Universiteit van Suid-Afrika) as Opvoedkundige sielkundige op die konsep van omgee gefokus het.

\section{Literatuurverwysings}

Angeli, D., 2014, 'A healthy dose of nature', The Biologist 61(1), 10-11.

Archer, J., Probert, B.S. \& Gage, L., 1987, 'College students' attitudes toward wellness', Journal of College Student Personnel 28(4), 311-317.

Bronfenbrenner, U., 1989, 'Ecological systems theory', in R. Vasta (ed.), Annals of child development, pp. 187-251, JAl Press, Greenwich, CT.

Callicot, J.B., 1996, 'Environmental wellness', Literature and Medicine 15(1), 146-160. http://dx.doi.org/10.1353/Im.1996.0002

Costanza, R., 2013, 'Sustainable wellbeing', Resurgence and Ecologist 279, 39-41.

Diener, E. \& Seligman, M.E.P., 2004, 'Beyond money - toward an economy of well-being', Psychological Science in Public Interest 5(1), 1-31. http://dx.doi. org/10.1111/j.0963-7214.2004.00501001.x

Donald, D., Lazarus, S. \& Lolwane, P., 2012, Educational psychology in social context - ecosystemic applications in Southern Africa, 4th edn., Oxford University Press, Cape Town.

Dunn, H.L., 1959, 'High-level wellness for man and society', American Journal of Public Health and the Nations Health 49(6), 786-792. http://dx.doi.org/10.2105/ AJPH.49.6.786

Goralnik, L., Millenbach, K.F., Nelson, M.P. \& Thorp, L., 2012, ‘An environmental pedagogy of care: emotion, relationships, and experience in higher education ethics learning', Journal of Experiential Education 35(3), 412-428. http://dx.doi. org/10.5193/JEE35.3.412

Hart, P., 2003, Teachers' thinking in environmental education, Peter Lang, New York, NY.

Heidegger, M., 1996, Being and time, State University of New York Press, New York, NY.

Keenan, T. \& Evans, S., 2009, An introduction to child development, SAGE, London.

Lin, B.B., Fuller, R.A., Bush, R., Gaston, K.J. \& Shanahan, D.F., 2014, 'Opportunity or orientation? Who uses urban parks and why?', PloS One 9(1), 1-7.

Louv, R., 2005, Last child in the woods: Saving our children from nature-deficit disorder, Algonquin Books, Chapel Hill, NC.

Millenium Ecosystem Assessment, 2005, Ecosystems and human well-being: Synthesis, Resources Institute, Washington, DC. 
Miller, J.W., 2005, 'Wellness: The history and development of a concept', Spektrum Freizeit 27, 84-106.

Mortari, L., 2004, 'Educating to care', Canadian Journal of Environmental Education 9, 109-122.

Myers, J.E., 1991, 'Wellness as the paradigm for counseling and development: The possible future', Counselor Education and Supervision 30, 183-193. http://dx.doi. org/10.1002/j.1556-6978.1991.tb01199.x

Nisbet, E.K., Zelenski, J.M. \& Murphy, S.A., 2011, 'Happiness is in our nature: Exploring nature relatedness as a contributor to subjective well-being', Journal of Happiness Studies 12(2), 303-322. http://dx.doi.org/10.1007/s10902-010-9197-7

Noddings, N., 1984, Caring: A feminine approach to ethics and moral education, University of California Press, Berkely, CA.

Noddings, N., 1992, The challenge to care in schools: an alternative approach to education, Teachers College Press, New York, NY.

Noddings, N., 2012, 'The language of care ethics', Knowledge Quest 40(4), 52-56.

Norström, A.V., Dannenberg, A., McCarney, G., Milkoreit, M., Diekert, F., Engström, G. et al., 2014, 'Three necessary conditions for establishing sustainable development goals in the anthropocene', Ecology and Society 19(3), 1-8. http://dx.doi. org/10.5751/ES-06602-190308

Prilleltensky, I., 2012, 'Wellness as fairness', American Journal of Community Psychology 49(1-2), 1-21. http://dx.doi.org/10.1007/s10464-011-9448-8
Reese, R.F. \& Myers, J.E., 2012, 'EcoWellness: The missing factor in holistic wellness models', Journal of Counselling and Development 90, 400-407. http://dx.doi. org/10.1002/j.1556-6676.2012.00050.x

Roszak,T., 1992, The voice of the earth: An exploration of ecopsychology, Phanes Press, Grand Rapids, MI.

Schuster-Gansrow, M.E., 2011, 'The pursuit of happiness: It's up to you', Campus Activities Programming 10, 31-34.

Summers, J.K., Smith, L.M., Case, J.L. \& Linthurst, R.A., 2012, 'A review of the elements of human well-being with an emphasis on the contribution of ecosystem services', Ambio 41, 327-340. http://dx.doi.org/10.1007/s13280-012-0256-7

Suzuki, D., 1997, National strategy for environmental education, Supply and Services, Ottowa, Canada.

Warner, M.J., 1984, 'Wellness promotion for higher education', National Association of Student Personnel Administrators Journal 2(3), 32-38.

Weinstein, E. \& Rosen, E., 2003, Teaching children about health, Wadsworth Cengage Learning, Belmont, CA.

Wells, N.M. \& Lekies, K.S., 2006, 'Nature and the life course: Pathways from childhood nature experiences to adult environmentalism', Children, Youth and Environments 16(1), 1-24.

Woolfolk, A., 2013, Educational Psychology, Pearson, Upper Saddle River, NJ.

Yang, W., Dietz, T., Kramer, D.B., Cheng, X. \& Liu, J., 2013, 'Going beyond the millenium ecosystem assessment: An index system of human well-being, PLoS One 8(5), 1-7. 